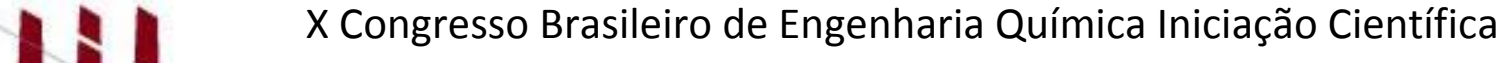 \\ "Influência da pesquisa em Engenharia Química no desenvolvimento tecnológico e industrial brasileiro" \\ Universidade Federal Rural do Rio de Janeiro Universidade Severino Sombra Vassouras - RJ-Brasil
}

\section{DESENVOLVIMENTO DE UM ALIMENTO FUNCIONAL A PARTIR DA DESIDRATAÇÃO OSMÓTICA E SECAGEM EM ESTUFA DA BETERRABA}

\author{
RIBEIRO $^{1}$, J.S.; MACAGNAN ${ }^{1}$, C.C.; PINHEIRO ${ }^{1}$, L.N.; FREITAS $^{1}$, M.S.; DRUZIAN ${ }^{1}$, S.P. \\ E TERRA ${ }^{2}$, L.M. \\ ${ }^{1}$ Aluna do DEQ/UFSM ${ }^{2}$ Professora do DEQ/UFSM \\ Departamento de Engenharia Química - Universidade Federal de Santa Maria \\ Endereço - DEQ/CT/UFSM, Av. Roraima, 1000, Camobi - Santa Maria, RS - CEP: 97105-900 \\ e-mail: lisianeterra@gmail.com
}

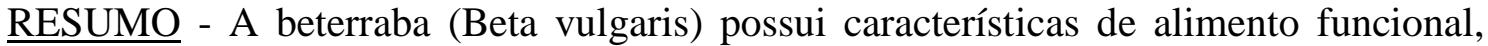
contendo substâncias bioativas e pigmentos com propriedades antioxidantes. A realização de um processo de desidratação osmótica seguido de secagem em túnel de vento apresenta-se como uma alternativa para obtenção de um produto que preserva suas características originais aumentando o tempo de conservação e vida útil. Visando definir as melhores condições de aplicação do processo de secagem, com objetivo de obter um alimento desidratado e funcional, encontrou-se como condições ótimas a desidratação osmótica em solução de $50^{\circ}$ Brix de sacarose $(97 \%)$ e cloreto de sódio (3\%), na proporção massa de solução por massa de alimento de 10:1, em uma temperatura de $40^{\circ} \mathrm{C}$ por 2 horas, e secagem em estufa a uma temperatura de $65^{\circ} \mathrm{C}$ por um período de tempo de 3 horas.
\end{abstract}

Palavras chave: beta vulgaris, bioativos, conservação.

\section{INTRODUÇÃO}

A beterraba (Beta vulgaris), hortaliça pertencente à família das Quenopodiáceas, possui características de alimento funcional, pois contém substâncias bioativas (licopeno) e pigmentos (carotenóides e flavonóides), que possuem propriedades antioxidantes e protegem contra doenças cardíacas, acidentes vasculares cerebrais, além de fortalecer o sistema imunológico (ARAUJO FILHO, 2008).

A secagem apresenta-se como alternativa para obtenção de um alimento funcional com boa estabilidade microbiológica e menor deterioração em relação ao produto in natura, aumentando o tempo de conservação e vida útil, além de facilitar o armazenamento e transporte. O processo envolveu um prétratamento de desidratação osmótica e a secagem propriamente dita, com o propósito de maximizar a perda de água do alimento.

A desidratação osmótica é uma técnica aplicada para remover água de alimentos frescos, colocando-os em contato com uma solução concentrada de maior pressão osmótica. Este método é utilizado como um pré-tratamento na secagem de frutas e vegetais para maximizar a remoção de água e minimizar as perdas de componentes e 
características originais do alimento como cor, sabor e textura (GOMES et al, 2007).

Apesar do processo de desidratação osmótica alcançar significativa perda de água e redução da atividade de água no alimento, este processo sozinho não alcança o nível desejado de conservação do alimento. Então, se faz necessária a posterior utilização de um processo de secagem para alcançar os níveis desejados.

A secagem é um termo mais restrito utilizado para designar a desidratação por meio do emprego de ar aquecido. É um processo de transferência simultânea de calor e massa, onde é requerida energia para evaporar a umidade da superfície do produto para o meio externo, convencionalmente o ar (PARK, COLATO E OLIVEIRA, 2007).

A análise de parâmetros como a atividade da água ao final de cada processo permite a avaliação da viabilidade do processo como um todo e a definição da melhor rota de secagem para obtenção de um alimento funcional a partir da beterraba.

\section{METODOLOGIA}

Foram utilizadas beterrabas de raiz vermelha obtidas em um mercado local da cidade de Santa Maria, Estado do Rio Grande do Sul e selecionadas de acordo com critérios de grau de maturação avançado (aproveitamento de matéria-prima de menor custo), tamanho, forma e aparência saudável, fatiadas com espessura de $3 \mathrm{~mm}$.

\section{Desidratação Osmótica}

A desidratação osmótica foi conduzida em um banho de 22 litros provido de agitação e utilizou como agente osmótico sacarose comercial $(97 \%)$ e cloreto de sódio (3\%), em solução.

A razão de massa de solução por massa do alimento foi de 10:1 e o tempo de imersão do alimento em solução de duas horas.

Através de um planejamento fatorial avaliou-se a influência das variáveis de entrada (temperatura e concentração da solução osmótica) sobre as variáveis respostas (perda de massa, perda de água, incorporação de sólidos, relação teor de sólidos solúveis e relação atividade de água).
Para tal avaliação aplicou-se um delineamento composto central rotacional (DCCR) com dois níveis originais, tendo assim 4 pontos fatoriais, 4 pontos axiais e 4 repetições do ponto central, e investigou o efeito da variação da temperatura $\left(30 \mathrm{a} 50^{\circ} \mathrm{C}\right)$ e da concentração da solução (40 a $60^{\circ}$ Brix).

Ao final da desidratação, as fatias foram retiradas da solução e secas superficialmente com papel absorvente, para serem submetidas à secagem em estufa.

\section{Secagem em estufa}

Primeiramente, foi estudada a cinética de secagem em estufa do produto desidratado osmoticamente, para melhor avaliar, projetar e otimizar o processo. Isto permitiu definir o intervalo de variação do novo DCCR, que teve como variáveis independentes: a temperatura $\left(40\right.$ a $\left.70^{\circ} \mathrm{C}\right)$ e tempo de secagem $(168,2$ a 240 min), e dependentes: porcentagem de massa perdida (redução de umidade) e redução de atividade da água, esta última medida no aparelho AquaLab.

\section{RESULTADOS E DISCUSSÕES}

\section{Desidratação osmótica}

Os modelos obtidos com parâmetros estatisticamente significativos $\quad(p<0,05)$ desenvolvidos para cada variável resposta a partir da regressão linear dos dados experimentais, utilizando o software Statistica 7.0, constam nas Equações 1 a 4.

Perda de água $=63,1976+3,3485^{*} \mathrm{C}-$ $1,5683 * \mathrm{C}^{2}+1,0503 * \mathrm{~T}-0,4491 * \mathrm{~T}^{2}-$ $0,555^{*} \mathrm{~T} * \mathrm{C}$

Incorporação de sólidos $=10,5900+1,4634 * \mathrm{C}$ $-0,2739 * \mathrm{C}^{2}+0,2610 * \mathrm{~T}-0,7115 * \mathrm{~T}^{2}+$ $1,1125 * \mathrm{~T} * \mathrm{C}$

Relação atividade de água $=0,9337$ $0,0194 * \mathrm{C}+0,0033 * \mathrm{C}^{2}-0,0050 * \mathrm{~T}+0,025 * \mathrm{~T}^{2}$ $-0,0085^{*} \mathrm{~T} * \mathrm{C}$

Relação teor sólidos solúveis $=5,8421+$ $0,5465 * \mathrm{C}-0,7424 * \mathrm{C}^{2}-0,0125 * \mathrm{~T}-$ $0,3803 * \mathrm{~T}^{2}+0,18 * \mathrm{~T} * \mathrm{C}$ 
Onde C corresponde à concentração de solução e $\mathrm{T}$ a temperatura, para valores das variáveis codificadas.

As Tabelas 1 e 2 mostram o efeito das variáveis independentes nas variáveis dependentes.

Tabela 1 - Efeito das variáveis independentes na perda de massa (PM) e na perda de água (PA).

\begin{tabular}{ccccc}
\hline Ensaio & $\mathrm{C}\left({ }^{\circ}\right.$ Brix $)$ & $\mathrm{T}\left({ }^{\circ} \mathrm{C}\right)$ & $\% \mathrm{PM}$ & $\% \mathrm{PA}$ \\
\hline 1 & 42,91 & 32,91 & 52,39 & 55,78 \\
\hline 2 & 42,91 & 47,09 & 55,78 & 60,67 \\
\hline 3 & 57,09 & 32,91 & 57,19 & 62,75 \\
\hline 4 & 57,09 & 47,09 & 58,47 & 65,42 \\
\hline 5 & 40 & 40 & 52,12 & 54,79 \\
\hline 6 & 60 & 40 & 59,93 & 65,42 \\
\hline 7 & 50 & 30 & 59,13 & 62,04 \\
\hline 8 & 50 & 50 & 57,8 & 62,62 \\
\hline $9(\mathrm{C})$ & 50 & 40 & 63,92 & 66,67 \\
\hline $10(\mathrm{C})$ & 50 & 40 & 63,73 & 66,12 \\
\hline $11(\mathrm{C})$ & 50 & 40 & 53,12 & 59,61 \\
\hline $12(\mathrm{C})$ & 50 & 40 & 55,28 & 60,39 \\
\hline & & & &
\end{tabular}

Tabela 2 - Efeito das variáveis de entrada na incorporação de sólidos (IS), relação teor de sólidos solúveis (RTSS) e relação de atividade de água (RAw).

\begin{tabular}{cccc}
\hline Ensaio & Inc. sólidos & RTSS & RAw \\
\hline 1 & 10,03 & 4,73 & 0,986 \\
\hline 2 & 7,57 & 3,89 & 0,981 \\
\hline 3 & 10,25 & 5,33 & 0,96 \\
\hline 4 & 12,24 & 5,21 & 0,921 \\
\hline 5 & 7,22 & 3,43 & 0,965 \\
\hline 6 & 12,03 & 5,16 & 0,916 \\
\hline 7 & 7,85 & 4,71 & 0,982 \\
\hline 8 & 9,66 & 5,32 & 0,985 \\
\hline $9(\mathrm{C})$ & 9,01 & 6,34 & 0,927 \\
\hline $10(\mathrm{C})$ & 9,73 & 6,59 & 0,925 \\
\hline $11(\mathrm{C})$ & 12,01 & 5,15 & 0,943 \\
\hline $12(\mathrm{C})$ & 11,62 & 5,29 & 0,94 \\
\hline
\end{tabular}

Analisando-se as tabelas anteriores, o ponto ótimo de operação do processo, em que se obteve maior perda de massa, perda de água e relação teor de sólidos solúveis, e menor incorporação de sólidos e relação atividade de água, foi obtido para uma concentração de 50 ${ }^{\circ}$ Brix e $40{ }^{\circ} \mathrm{C}$.

$\mathrm{Na}$ desidratação a $40{ }^{\circ} \mathrm{C}$, um aumento da concentração da solução para $60{ }^{\circ}$ Brix ocasionou uma diminuição da perda de massa, o que pode ter ocorrido como consequência da impregnação de sólidos na camada superficial das amostras de beterraba, o que dificulta a perda de massa (AZEREDO, 2000).

\section{Secagem em estufa}

Os modelos obtidos com parâmetros estatisticamente significativos desenvolvidos para cada variável resposta a partir da regressão linear dos dados experimentais, utilizando o software Statistica 7.0, constam nas Equações 5 e 6.

Perda de massa $=58,34561+8,15458 * \mathrm{~T}-$ $5,44078 * \mathrm{~T}^{2}+7,22639 * \mathrm{t}-5,30510 * \mathrm{t}^{2}-$ $5,71129 * \mathrm{~T} * \mathrm{t}$

$\mathrm{RAw}=0,494111+0,161505 * \mathrm{~T}$ $0,046556 * \mathrm{~T}^{2}+0,127738 * \mathrm{t}-0,035806 * \mathrm{t}^{2}-$ $0,089417 * \mathrm{~T} * \mathrm{t}$

Onde t corresponde ao tempo de secagem e $\mathrm{T}$ a temperatura de secagem, para valores das variáveis codificadas.

A Tabela 3 apresenta os valores obtidos para variáveis dependentes na secagem em estufa.

Tabela 3 - Dados secagem em estufa.

\begin{tabular}{cccc}
\hline $\mathrm{T}\left({ }^{\circ} \mathrm{C}\right)$ & $\mathrm{t}(\mathrm{min})$ & $\begin{array}{c}\% \text { Perda de } \\
\text { massa }\end{array}$ & $\begin{array}{c}\text { Atividade da } \\
\text { água }\end{array}$ \\
\hline 44.36 & 94.8 & 69.69 & 0.8713 \\
\hline 44.36 & 265.2 & 80.92 & 0.4653 \\
\hline 65.64 & 94.8 & 79.34 & 0.4267 \\
\hline 65.64 & 265.2 & 79.32 & 0.3783 \\
\hline 40 & 180 & 66.56 & 0.8987 \\
\hline 70 & 180 & 82.44 & 0.3610 \\
\hline 55 & 60 & 67.72 & 0.8090 \\
\hline 55 & 300 & 80.21 & 0.4077 \\
\hline 55 & 180 & 79.70 & 0.5173 \\
\hline 55 & 180 & 78.93 & 0.4927 \\
\hline 55 & 180 & 79.87 & 0.4747 \\
\hline
\end{tabular}

O ponto ótimo da análise das variáveis temperatura e tempo foi determinado como a região de sobreposição dos gráficos de redução de umidade e redução da atividade de água para uma mesma temperatura, levando às maiores reduções. 
Combinando todas as variáveis, o ponto ótimo de secagem é obtido para temperatura próxima a $65^{\circ} \mathrm{C}$ por um período de 3 horas.

\section{CONCLUSÕES}

O estudo mostrou a importância da desidratação osmótica realizada previamente à secagem em estufa. O pré-tratamento auxiliou na perda de água inicial, contribuindo para a redução de atividade de água. O ponto ótimo para desidratação osmótica corresponde a uma concentração de $50^{\circ}$ Brix, a uma temperatura de $40^{\circ} \mathrm{C}$.

$\mathrm{O}$ processo de secagem se mostrou eficiente no que diz respeito à conservação do alimento, visto que em determinadas faixas de temperatura e tempo de exposição ao processo apresentou baixos valores de atividade de água, variável importante no que diz respeito a conservação de alimentos, objetivo deste trabalho. $\mathrm{O}$ ponto ótimo de secagem foi obtido para uma temperatura de $65^{\circ} \mathrm{C}$ por 3 horas.

Dessa forma, foi possível alcançar o objetivo do trabalho, que visava obter um alimento com boa estabilidade microbiológica, conservando as características de alimento funcional.

\section{REFERÊNCIAS}

ANTONIO, G.C. et al. "Osmotic dehydration of sweet potato (Ipomoea batatas in ternary solutions)". Ciência e Tecnologia de Alimentos, Campinas, v. 28, n. 3, 2008.

ARAUJO FILHO, D. G. Obtenção de produto farináceo a partir de beterrabas submetidas à secagem estacionária. 2008. 57 f. Tese (Mestrado em Agronomia) UEPG, 2008.

AZEREDO, H. M. C.; JARDINE, J. G.

"Desidratação osmótica de abacaxi aplicada a tecnologia de métodos combinados". Ciência e Tecnologia de Alimentos, Campinas, v. 20, n. 1, p. 7482, 2000.

GERMER, S. P. M. et al. "Process variables in the osmotic dehydration of sliced peaches". Ciência e Tecnologia de Alimentos, Campinas, vol. 30, n. 4, 2010.

GOMES, A.T.; CEREDA, M.P.; VILPOUX, O. "Desidratação osmótica: uma tecnologia de baixo custo para desenvolvimento da agricultura familiar." Revista Brasileira de Gestão e Desenvolvimento Regional, v.3, n. 3, p. 212-226, 2007.

PARK, K.J.; COLATO, A.; OLIVEIRA, R.A. Conceitos de processos e equipamentos de secagem. Campinas, v. 1, 2007.

PONTING, J. D. et al. "Osmotic Dehydration of Fruits". Food Technology, v.20, p.125$128,1966$. 